\title{
Comparison of difficulty with activities of daily living in elderly adults undergoing hemodialysis and community-dwelling individuals: a cross-sectional study
}

Toshiki Kutsuna ${ }^{1,2^{*}}$ (D), Yusuke Isobe ${ }^{2}$, Takaaki Watanabe ${ }^{2}$, Yusuke Matsunaga ${ }^{3,4}$, Satomi Kusaka ${ }^{1}$, Yasuaki Kusumoto', Junko Tsuchiya ${ }^{1}$, Masaru Umeda ${ }^{1}$, Hiroyuki Watanabe ${ }^{5}$, Shinobu Shimizu ${ }^{5}$, Atsushi Yoshida ${ }^{6}$ and Atsuhiko Matsunaga 2,5

\begin{abstract}
Background: Elderly adults undergoing hemodialysis (HD) have multiple comorbidities, physical frailty, and functional dependence with activities of daily living (ADL). ADL difficulty is an early predictor of ADL dependency in community-dwelling elderly adults. However, the characteristics of ADL difficulty in patients undergoing HD have not yet been reported. The present study aimed to examine the current status and characteristics of physical function and ADL difficulty in ambulatory elderly patients undergoing HD.

Methods: In all, 136 elderly outpatients undergoing HD and 40 community-dwelling controls participated in the present study. The characteristics, physical function (SARC-F score, grip strength, five-times sit-to-stand test time, usual gait speed, maximum gait speed, and short physical performance battery score), and scores from the ADL difficulty questionnaires [difficulty related to upper limb $(\mathrm{U} / \mathrm{L})$ and lower limb $(\mathrm{L} / \mathrm{L})$ functions] were compared between the HD and control groups. Multiple regression analysis was performed to examine whether the characteristics of physical function were able to discriminate ADL difficulty in the HD group.

Results: The HD group had a significantly greater SARC-F score, lower grip strength, longer five-times sit-to-stand test time, slower usual gait speed, slower maximum gait speed, lower short physical performance battery score, and lower $U / L$ and $L / L A D L$ difficulty scores compared to the control group (all $P<0.001$ ). The distribution of $U / L$ and $L / L$ ADL difficulty scores showed a wider variation in the HD group than in the control group. The U/L ADL difficulty score was independently associated with the SARC-F score $(\beta=-0.52, P<0.001)$ and grip strength $(\beta=0.21, P=0.02)$. The $L / L A D L$ difficulty score was independently associated with the SARC-F score $(\beta=-0.56, P<0.001)$ and usual gait speed $(\beta=0.35, P<0.001)$.

Conclusions: The elderly HD group had a poorer physical function and experienced stronger ADL difficulty than the control group. There was an association between ADL difficulty and sarcopenia or poor physical function among patients undergoing HD. These findings provide useful data for effective clinical management to prevent decline of ADL in ambulatory elderly patients undergoing HD.
\end{abstract}

Keywords: Activities of daily living, Difficulty, Elderly, Hemodialysis, Muscle strength, Physical function, Questionnaire, Sarcopenia, Walking ability

\footnotetext{
* Correspondence: t.kutsuna.1981@gmail.com

1 Department of Physical Therapy, School of Health Sciences, Tokyo University

of Technology, 5-23-22 Nishikamata, Ota-ku, Tokyo 144-8535, Japan

${ }^{2}$ Department of Rehabilitation Sciences, Kitasato University Graduate School

of Medical Sciences, Sagamihara, Kanagawa, Japan

Full list of author information is available at the end of the article
}

(c) The Author(s). 2020 Open Access This article is distributed under the terms of the Creative Commons Attribution 4.0 International License (http://creativecommons.org/licenses/by/4.0/), which permits unrestricted use, distribution, and reproduction in any medium, provided you give appropriate credit to the original author(s) and the source, provide a link to the Creative Commons license, and indicate if changes were made. The Creative Commons Public Domain Dedication waiver (http://creativecommons.org/publicdomain/zero/1.0/) applies to the data made available in this article, unless otherwise stated. 


\section{Background}

National and international surveys, such as the Dialysis Outcomes and Practice Pattern Study, showed that the number of elderly adults undergoing hemodialysis (HD) has been increasing all over the world in recent years [1, 2]. Elderly patients undergoing HD are characterized by multiple comorbidities [1, 3], physical frailty $[4,5]$, and high burden of functional dependence with activities of daily living (ADL) [5, 6]. In a prospective cohort study, the appearance of physical frailty, such as slower gait speed, was one of the factors for ADL dependency [7]. Moreover, it was shown that ADL dependency deteriorated the quality of life and increased the risk of mortality $[8,9]$. Therefore, there is a need for measures to predict and detect ADL dependency in advance for elderly patients undergoing HD.

The guidelines of European Renal Best Practice, a clinical practice guideline on the management of older patients with chronic kidney disease, recommended measuring the ADL level regularly similar to that for physical function in elderly patients [10]. Moreover, the Japanese Society of Renal Rehabilitation has encouraged the evaluation of ADL level along with physical function and quality of life as outcome measures of renal rehabilitation in the clinical practice guideline for renal rehabilitation [11]. In a report on community-dwelling elderly adults, mobility difficulties were shown as an early predictor of ADL dependency [12]. Although the evaluation of ADL difficulty such as mobility difficulty is considered important for the prediction and early detection of ADL dependency, almost all reports concerning ADL level in patients undergoing HD have focused on ADL dependency $[5-9,13,14]$. A few studies reported that most of these patients who had no ADL dependency experienced difficulty when performing some ADL $[15,16]$. However, the results were limited because of the lack of control participants. We believe that evaluating the current status and characteristics of ADL difficulty in elderly patients undergoing HD is essential for the improvement of the patient's treatment environment and life.

The present study aimed to examine the current status and characteristics of ADL difficulty in ambulatory elderly patients undergoing HD by comparing the physical functions and ADL difficulties between elderly adults undergoing $\mathrm{HD}$ and community-dwelling individuals as control.

\section{Methods}

\section{Participants and study design}

Japanese elderly adults who were 65 years or older were included in the present study. Outpatients undergoing $\mathrm{HD}$ at one dialysis unit were recruited as the study participants. All patients were undergoing maintenance HD therapy thrice a week and were clinically stable. Patients were excluded if they were within 3 months of dialysis initiation, were hospitalized within 3 months prior to the study, and had severe arthralgia or myalgia, severe motor paralysis, and severe dementia. We posted information regarding the recruitment of study participants in the community bulletin and targeted elderly adults who volunteered for the study as the control group. The control participants were able to come to the venue for assessment independently and were excluded if they had the following medical history: orthopedic diseases, cardiovascular diseases, respiratory diseases, central nervous system diseases, or diabetes mellitus.

This was a cross-sectional study, and all data were collected from May 2017 to February 2019. The purpose of the study was explained to all the participants and written informed consent was obtained. The present study was performed according to the guidelines of the Declaration of Helsinki and approved by the research ethics committees of Kitasato University (approval number: 2016-014) and Tokyo University of Technology (approval number: E18HS-018).

\section{Characteristics}

Patient characteristics including age, sex, height, body weight, body mass index, and living alone status (yes or no) were collected for both the HD and control groups. The duration of HD, primary kidney disease, comorbid condition, serum albumin levels, and blood hemoglobin levels were investigated from the clinical records only in the HD group. The comorbid condition was evaluated using a comorbidity index score developed for dialysis patients consisting of primary kidney disease and 11 comorbidities [17].

\section{Physical function}

We evaluated the subjects using SARC-F, which was developed and validated as a screening tool for sarcopenia. The SARC-F is a self-administered questionnaire and has five items, including strength, assistance in walking, rise from a chair, climb stairs, and falls. The scale scores ranged from 0 to 2 points for each item [18]. The total score ranged from 0 to 10 points (i.e., $0=$ best, $10=$ worst), and score of $\geq 4$ points indicate the risk of sarcopenia [19].

Grip strength was measured as an indicator of muscle strength of the upper limb using a digital dynamometer (Grip D; Takei Scientific Instruments, Niigata, Japan). Participants were asked to grip a dynamometer as tightly as possible for $3 \mathrm{~s}$ with the elbow joint fixed at $90^{\circ}$ in the sitting position [20]. Grip strength was measured twice on each hand and the highest value $(\mathrm{kg})$ was used in the analysis. A grip strength of $<26 \mathrm{~kg}$ (for men) and $<18 \mathrm{~kg}$ (for women) are considered the cut-off values of sarcopenia diagnosis [21]. 
The five-times sit-to-stand test time was measured as an indicator of muscle strength of the lower limb using a stopwatch and a chair with a seat of $40 \mathrm{~cm}$. Participants were asked to stand up five times as quickly as possible with their arms across in front of the chest [22]. The time from the first sitting position to the fifth standing position was measured twice, and the fastest value (s) was used in the analysis.

The usual gait speed and maximum gait speed were measured as indicators of walking ability using a stopwatch. Participants were asked to walk down a 10-m walkway with an acceleration area at their self-chosen usual speed, and maximum speed without running [23]. Each test was measured twice and the faster values $(\mathrm{m} / \mathrm{s})$ for each gait speed were used in the analysis. The usual gait speed of $<0.8 \mathrm{~m} / \mathrm{s}$ was used as the cut-off value of sarcopenia diagnosis [21], and $\leq 1.0 \mathrm{~m} / \mathrm{s}$ indicated the risk of hospitalization and decline in health status [24]. The maximum gait speed of $\leq 1.50 \mathrm{~m} / \mathrm{s}$ (for men) and $\leq 1.35 \mathrm{~m} / \mathrm{s}$ (for women) are suggestive of the risk of cardiovascular mortality [25].

The short physical performance battery (SPPB) score was measured as an indicator of lower limb function. The SPPB consists of three components, including standing balance, usual gait speed, and five-times sit-tostand test time. The scale scores ranged from 0 to 4 points for each component [26]. The total score ranged from 0 to 12 points (i.e., 0 = worst, 12 = best), and score of $\leq 9$ points indicated the risk of walking disability [27].

\section{ADL difficulty questionnaire}

ADL dependency and ADL difficulty are widely used to assess ADL ability. ADL dependency is evaluated as the amount of supervision or assistance required with ADL tasks, while ADL difficulty is evaluated as the perceived difficulty encountered when performing ADL tasks.

$\mathrm{ADL}$ difficulty was evaluated with two questionnaires developed for patients undergoing assessment of their perceived difficulty in performing ADL related to upper-limb function (U/L ADL difficulty) and lower-limb function (L/ L ADL difficulty) $[16,28]$. The participants were asked to rate their perceived difficulty in performing each item on a scale of 1 to 5 (1, not possible; 2 , severe difficulty; 3 , moderate difficulty; 4 , mild difficulty; 5 , ease).

U/L ADL difficulty questionnaire consisted of two components, including light work and holding activities, and each component had six and five items, respectively [28]. U/L ADL difficulty score was the sum of all points in 11 items and ranged from 11 to 55 points (i.e., $11=$ worst, 55 = best). L/L ADL difficulty questionnaire consisted of three components, including basic ADL, ambulation, and walking up or down stairs, and each component had three, five, and four items, respectively [16]. L/L ADL difficulty score was the sum of all points in 12 items and ranged from 12 to 60 points (i.e., $12=$ worst, 60 = best).

\section{Statistical analysis}

Sample size calculation was performed using the data of the L/L ADL difficulty score in a previous study [16]. The number of participants in the HD group was set to three times that of the control group because the multivariate analysis was performed using the data of the HD group. We calculated a target sample size of 111 participants in the HD group and 37 participants in the control group to provide $80 \%$ power to detect a 5.7 point difference between the HD and control groups, with a two-sided alpha level of 0.05 using a standard deviation of 10.6.

The characteristics, physical function, and ADL difficulty were compared between the HD and control groups using the Student $t$ test, Mann-Whitney $U$ test, and chi-square test. The median score of each item of ADL difficulty and score distribution of each item were compared between the HD and control groups using the Mann-Whitney $U$ test and chi-square test. To compare the score distribution of the ADL difficulty scores, histograms of U/L, and L/L ADL difficulty scores were created at 5-point intervals. Simple and multiple regression analyses were performed to predict $\mathrm{U} / \mathrm{L}$ and $\mathrm{L} / \mathrm{L} \mathrm{ADL}$ difficulty scores using age, sex, body mass index, living alone status, SARC-F score, HD status (yes or no), grip strength, and usual gait speed. Correlations between physical functions and ADL difficulty scores were analyzed by calculating Spearman's correlation coefficients, and scatter plots were drawn for visualization.

Unless otherwise stated, the data are presented as mean \pm standard deviation, number (percentage), or median (interquartile range). Statistical significance was set at a $P$ value of $<0.05$. All analyses were performed using $\mathrm{JMP}^{\star}$ (JMP pro version 14; SAS Institute Inc., Cary, NC, USA).

\section{Results}

In all, 136 outpatients undergoing HD and 40 healthy individuals as controls were recruited in the present study. The characteristics, physical function, and ADL difficulty of the study participants are shown in Table 1 . In the HD group, the mean age was $73.8 \pm 6.7$ years, $52.3 \%$ of patients were men, the mean body mass index was 21.4 $\pm 3.4 \mathrm{~kg} / \mathrm{m}^{2}$, and the median duration on HD was 7.5 (3.0-13.5) years. There were no significant differences in characteristics between the HD and control groups. The HD group had a significantly greater SARC-F score, lower grip strength, longer five-times sit-to-stand test time, slower usual gait speed, slower maximum gait speed, lower SPPB score, and lower ADL difficulty scores than the control group (all $P<0.001$ ). 
Table 1 Characteristics, physical function, and ADL difficulty of study participants

\begin{tabular}{|c|c|c|c|}
\hline & $\begin{array}{l}\text { Hemodialysis group } \\
(n=136)\end{array}$ & $\begin{array}{l}\text { Control group } \\
(n=40)\end{array}$ & $P$ value \\
\hline Age (years) & $73.8 \pm 6.7$ & $75.4 \pm 5.8$ & 0.16 \\
\hline 65 to 74 & $78(57.4)$ & $17(42.5)$ & \\
\hline$\geq 75$ & $58(42.6)$ & $23(57.5)$ & \\
\hline Men & $72(52.3)$ & $20(50.0)$ & 0.74 \\
\hline Height (m) & $1.59 \pm 0.09$ & $1.58 \pm 0.09$ & 0.30 \\
\hline Body weight (kg) & $54.6 \pm 11.0$ & $55.5 \pm 8.0$ & 0.63 \\
\hline Body mass index $\left(\mathrm{kg} / \mathrm{m}^{2}\right)$ & $21.4 \pm 3.4$ & $22.3 \pm 2.3$ & 0.11 \\
\hline$<18.5$ & $32(23.5)$ & $2(5.0)$ & \\
\hline 18.5 to 24.9 & $85(62.5)$ & $35(87.5)$ & \\
\hline$\geq 25.0$ & $19(14.0)$ & $3(7.5)$ & \\
\hline Duration of hemodialysis (years) & $7.5(3.0,13.5)$ & - & - \\
\hline Primary kidney disease & & - & - \\
\hline Glomerulonephritis & $39(28.7)$ & & \\
\hline Diabetes & 47 (34.6) & & \\
\hline Hypertension & $9(6.6)$ & & \\
\hline Other & $23(16.9)$ & & \\
\hline Unknown & $18(13.2)$ & & \\
\hline Comorbidity index score (points) & $7(5,9)$ & - & - \\
\hline Albumin (g/dL) & $3.7 \pm 0.3$ & - & - \\
\hline Hemoglobin (g/dL) & $10.8 \pm 0.9$ & - & - \\
\hline Living alone & $34(25.0)$ & $5(12.5)$ & 0.08 \\
\hline SARC-F score (points) & $3(1,5)$ & $1(0,2)$ & $<0.001$ \\
\hline$\geq 4$ & $58(42.6)$ & $1(2.5)$ & \\
\hline Grip strength (kg) & $21.6 \pm 7.1$ & $26.7 \pm 6.6$ & $<0.001$ \\
\hline Male $<26$, female $<18$ & $82(60.3)$ & $7(17.5)$ & \\
\hline Five-times sit-to-stand test time $(\mathrm{s}){ }^{*}$ & $11.2 \pm 4.6$ & $6.5 \pm 2.6$ & $<0.001$ \\
\hline Usual gait speed (m/s) & $1.04 \pm 0.31$ & $1.59 \pm 0.27$ & $<0.001$ \\
\hline$<0.8$ & $29(21.3)$ & $0(0.0)$ & \\
\hline$\leq 1.0$ & $59(43.4)$ & $0(0.0)$ & \\
\hline Maximum gait speed (m/s) & $1.35 \pm 0.43$ & $2.00 \pm 0.39$ & $<0.001$ \\
\hline Male $\leq 1.50$, female $\leq 1.35$ & $75(55.1)$ & $1(2.5)$ & \\
\hline SPPB score (points) & $11(8,12)$ & $12(12,12)$ & $<0.001$ \\
\hline$\leq 9$ & $46(33.8)$ & $0(0.0)$ & \\
\hline U/L ADL difficulty score (points) & $40(31,49)$ & $52(45,54)$ & $<0.001$ \\
\hline Light work & $22(18,27)$ & $28(22,30)$ & $<0.001$ \\
\hline Holding activities & $18(14,22)$ & $24(21,25)$ & $<0.001$ \\
\hline L/L ADL difficulty score (points) & $41(30,50)$ & $56(51,58)$ & $<0.001$ \\
\hline Basic ADL & $11(9,13)$ & $14(12,15)$ & $<0.001$ \\
\hline Ambulation & $18(12,24)$ & $25(21,25)$ & $<0.001$ \\
\hline Walking up or down stairs & $13(10,16)$ & $19(16,20)$ & $<0.001$ \\
\hline
\end{tabular}

Values are presented as mean \pm standard deviation, number (percentage), or median (interquartile range)

*Twelve hemodialysis patients could not complete the five-times sit-to-stand test.

$A D L$ : activities of daily living, $L / L$ : lower limb, SPPB: Short physical performance battery, $U / L$ : upper limb 
The scores of the items of the ADL difficulty questionnaire are shown in Table 2 . The scores of 10 out of 11 items in the U/L ADL difficulty were significantly lower in the HD group than in the control group (all $P<0.01$ ). The scores of all 12 items in the L/L ADL difficulty were significantly lower in the HD group than in the control group (all $P<0.001$ ).

The score distribution of the items in the ADL difficulty questionnaire is shown in Fig. 1. For U/L ADL difficulty, the HD group found "Opening a jar that has a tight lid" the most difficult of all 11 items. In the $\mathrm{L} / \mathrm{L}$ ADL difficulty, the HD group found "Walking up two flights of stairs" as the most difficult of all 12 items. The proportion of patients in the HD group who experienced more difficulty performing each U/L ADL item was significantly higher than that in the control group for all 11 items (all $P<0.05$ ). The proportion of patients in the HD group who experienced more difficulty in performing each $\mathrm{L} / \mathrm{L}$ ADL item was significantly higher than that in the control group for all 12 items (all $P<0.005$ ).

The histogram of the ADL difficulty score is shown in Fig. 2. The distribution of U/L and L/L ADL difficulty scores showed a wider variation in the HD group than in the control group. In the U/L ADL, $11.0 \%$ and $20.0 \%$ scored full points (55 points) in the HD and control groups, respectively. In the $\mathrm{L} / \mathrm{L} \mathrm{ADL}, 8.8 \%$ and $15.0 \%$

Table 2 Score of the items in the ADL difficulty questionnaire

\begin{tabular}{|c|c|c|c|}
\hline & $\begin{array}{l}\text { Hemodialysis group } \\
(n=136)\end{array}$ & $\begin{array}{l}\text { Control group } \\
(n=40)\end{array}$ & $P$ value \\
\hline \multicolumn{4}{|l|}{ a: U/L ADL difficulty } \\
\hline \multicolumn{4}{|l|}{ Light work } \\
\hline U-1 Gardening or doing yard work & $4(3,5)$ & $5(4,5)$ & 0.003 \\
\hline U-2 Carrying a heavy object (over 5 kg) & $4(3,5)$ & $4.5(3,5)$ & 0.06 \\
\hline U-3 Making a bed & $4(3,5)$ & $5(5,5)$ & $<0.001$ \\
\hline U-4 Doing heavy household chores & $4(3,5)$ & $5(3.25,5)$ & 0.001 \\
\hline U-5 Changing a lightbulb overhead & $4(3,5)$ & $5(4,5)$ & $<0.001$ \\
\hline U-6 Pushing and opening a heavy door & $4(3,5)$ & $5(4,5)$ & 0.003 \\
\hline \multicolumn{4}{|l|}{ Holding activities } \\
\hline U-7 Unscrewing a PET bottle cap & $4(3,5)$ & $5(4,5)$ & $<0.001$ \\
\hline U-8 Opening a pull-tab can & $4(3,5)$ & $5(4,5)$ & $<0.001$ \\
\hline U-9 Opening a new milk carton & $4(3,5)$ & $5(5,5)$ & $<0.001$ \\
\hline U-10 Using a frying pan with one hand & $4(3,5)$ & $5(4,5)$ & $<0.001$ \\
\hline U-11 Opening a jar that has a tight lid & $3(2,4)$ & $4(4,5)$ & $<0.001$ \\
\hline \multicolumn{4}{|l|}{ b: L/L ADL difficulty } \\
\hline \multicolumn{4}{|l|}{ Basic ADL } \\
\hline L-1 Rising from a chair & $4(3,5)$ & $5(5,5)$ & $<0.001$ \\
\hline $\mathrm{L}-2$ Rising from the floor & $3(3,4)$ & $4(4,5)$ & $<0.001$ \\
\hline L-3 Sitting on the floor & $3.5(3,5)$ & $5(4,5)$ & $<0.001$ \\
\hline \multicolumn{4}{|l|}{ Ambulation } \\
\hline L-4 Walking 100 m & $4(3,5)$ & $5(4,5)$ & $<0.001$ \\
\hline L-5 Walking 300 m & $4(2.25,5)$ & $5(4,5)$ & $<0.001$ \\
\hline L-6 Walking 600 m & $3(2,5)$ & $5(4,5)$ & $<0.001$ \\
\hline L-7 Walking 1 km & $3(1,4.75)$ & $5(4,5)$ & $<0.001$ \\
\hline L-8 Walking 20 m quickly & $4(3,5)$ & $5(4,5)$ & $<0.001$ \\
\hline \multicolumn{4}{|l|}{ Walking up or down stairs } \\
\hline L-9 Walking up one flight of stairs & $3(3,4)$ & $5(4,5)$ & $<0.001$ \\
\hline L-10 Walking up two flights of stairs & $3(2,4)$ & $4(4,5)$ & $<0.001$ \\
\hline L-11 Walking down one flight of stairs & $4(3,5)$ & $5(4,5)$ & $<0.001$ \\
\hline L-12 Walking down two flights of stairs & $3(2,4)$ & $5(4,5)$ & $<0.001$ \\
\hline
\end{tabular}

Values are presented as median (interquartile range) 


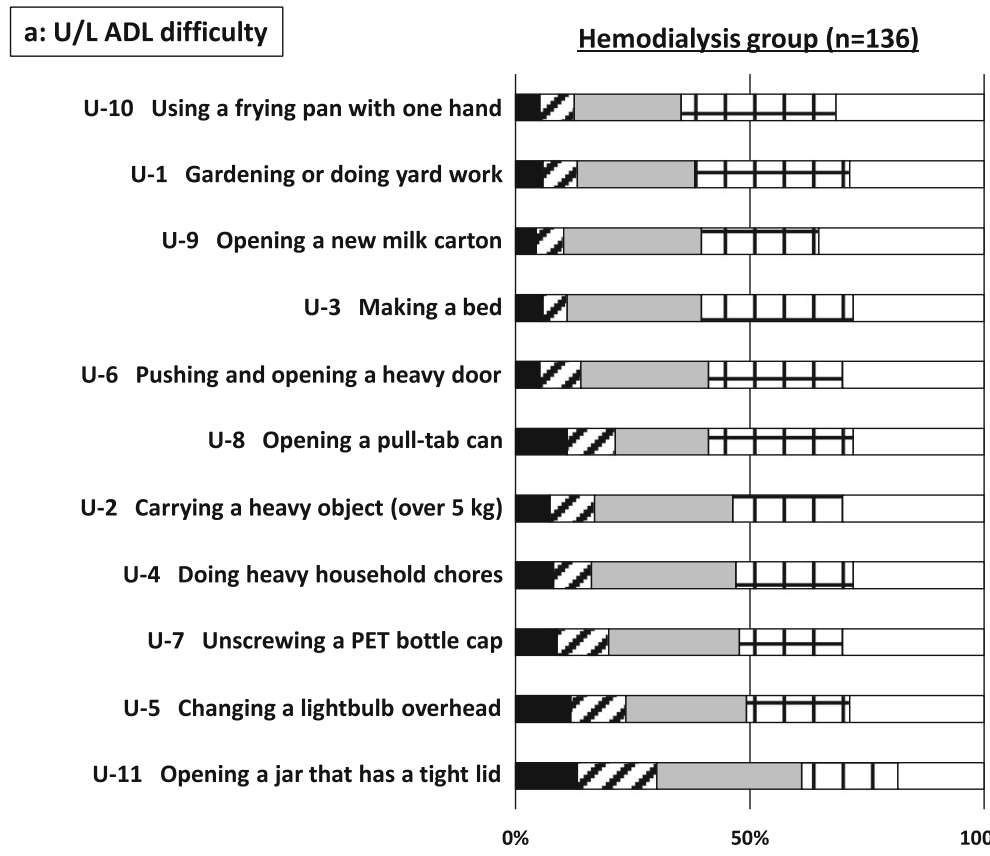

Percentage of participants

b: L/L ADL difficulty

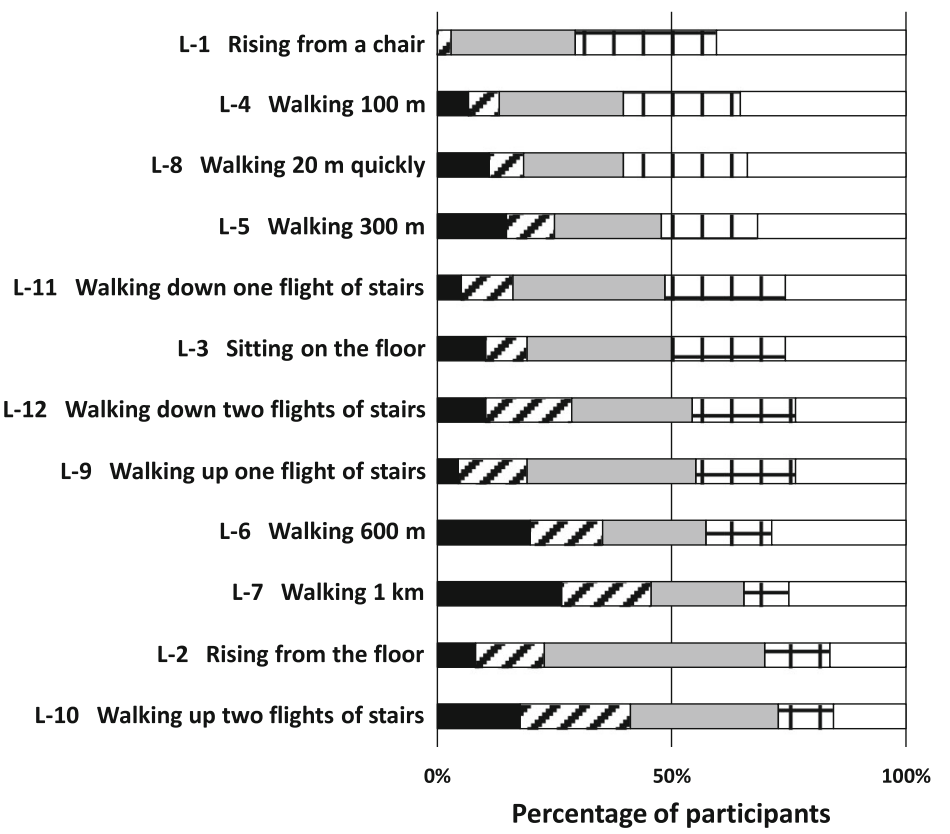

Control group $(n=40)$

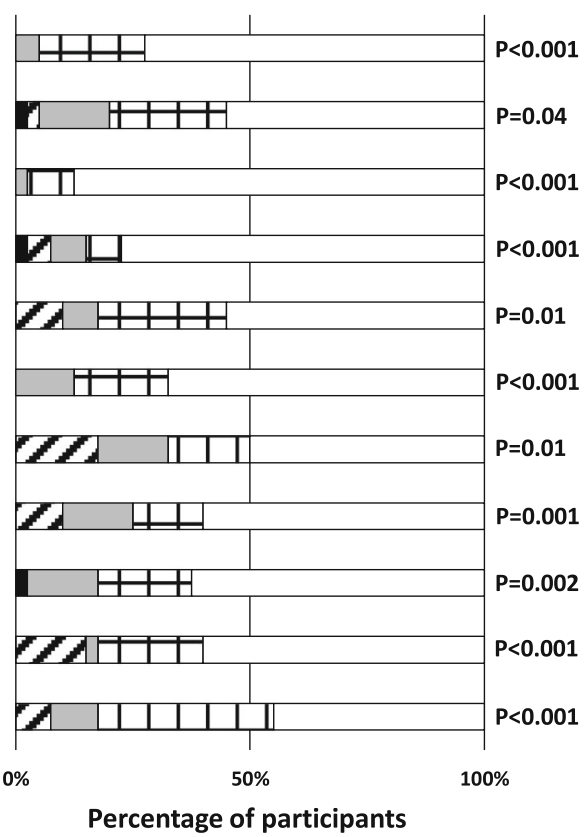

Control group $(n=40)$

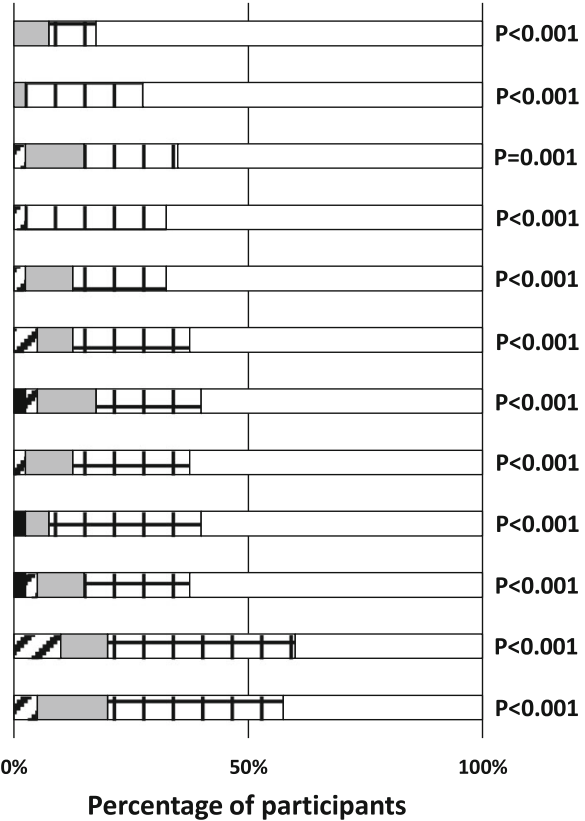

Percentage of participants

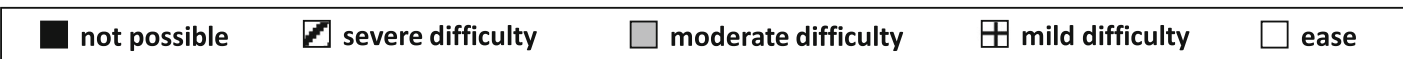

Fig. 1 Score distribution of the items of the ADL difficulty questionnaire. ADL: activities of daily living, L/L: Lower limb, U/L: upper limb

scored full points (60 points) in the $\mathrm{HD}$ and control groups, respectively.

The results of simple and multiple regression analyses for the effect on ADL difficulty score are shown in Table 3 . The age $(\beta=-0.25, P=0.001)$, sex $(\beta=0.16, P=0.04)$, body mass index $(\beta=0.23, P=0.002)$, SARC-F score $(\beta=$ $-0.70, P<0.001)$, HD or not $(\beta=-0.34, P<0.001)$, grip strength $(\beta=0.50, P<0.001)$, and usual gait speed $(\beta=$ $0.53, P<0.001)$ were significant predictors of the U/L ADL difficulty score in univariate analysis. The SARC-F 


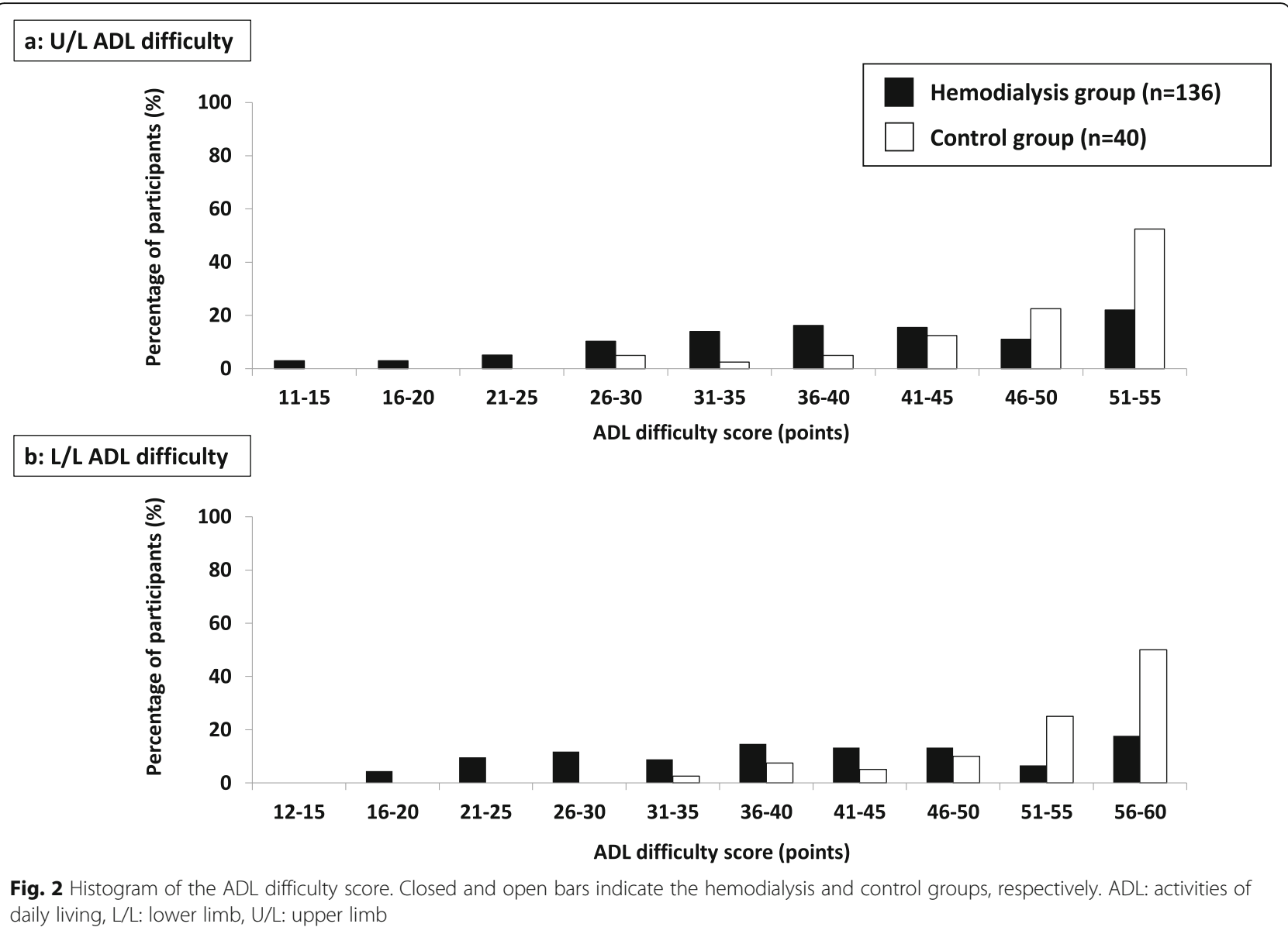

score $(\beta=-0.52, P<0.001)$ and grip strength $(\beta=$ $0.21, P=0.02)$ remained significant predictors of the U/L ADL difficulty score after adjusting for age, sex, body mass index, living alone status, HD status, and usual gait speed. Age $(\beta=-0.24, P=0.002)$, SARC-F score $(\beta=-0.78$, $P<0.001)$, HD status $(\beta=-0.43, P<0.001)$, grip strength $(\beta=0.36, P<0.001)$, and usual gait speed $(\beta=$ $0.72, P<0.001)$ were significant predictors of $\mathrm{L} / \mathrm{L} \mathrm{ADL}$ difficulty score in the univariate analysis. SARC-F score $(\beta=-0.56, P<0.001)$ and usual gait speed $(\beta=0.35$, $P<0.001)$ remained significant predictors of the $\mathrm{L} / \mathrm{L}$ ADL difficulty score after adjusting for age, sex, body mass index, living alone status, HD status, and grip strength.

The scatter plots of physical function and ADL difficulty score in the HD group are shown in Fig. 3. The U/ L ADL difficulty score was significantly correlated with the SARC-F score $\left(\mathrm{r}_{\mathrm{s}}=-0.63, P<0.001\right)$ and grip strength $\left(\mathrm{r}_{\mathrm{s}}=0.45, P<0.001\right)$. The $\mathrm{L} / \mathrm{L}$ ADL difficulty score was significantly correlated with the SARC-F score $\left(\mathrm{r}_{\mathrm{s}}=-0.75, P<0.001\right)$, five-times sit-to-stand test time $\left(\mathrm{r}_{\mathrm{s}}=-0.52, P<0.001\right)$, usual gait speed $\left(\mathrm{r}_{\mathrm{s}}=0.66, P<0.001\right)$, maximum gait speed $\left(\mathrm{r}_{\mathrm{s}}=0.67, P<0.001\right)$, and SPPB score $\left(\mathrm{r}_{\mathrm{s}}=0.61, P<0.001\right)$.

\section{Discussion}

This study investigated the characteristics of ADL difficulty in ambulatory elderly patients undergoing HD by comparing with a control group. The present study showed that physical function, such as muscle strength and walking ability, in these patients was markedly lower than that of control individuals, and most patients had a physical function below the cut-off values for the risk of sarcopenia, disability, or mortality. Moreover, patients experienced more difficulty with various ADL tasks compared to the control individuals, and their ADL difficulty was correlated with the indicators of sarcopenia and deterioration of physical function.

The control group showed a predominance of "ease" and "mild difficulty" in each item of U/L and L/L ADL difficulty, although the difficulty was widely dispersed from "ease" to "not possible" in the HD group. Furthermore, the U/L and L/L ADL difficulty scores were broadly distributed in the HD group, while the scores were inclined towards the higher side in the control group. In a cross-sectional study, it was reported that many patients exhibited ADL difficulty even if they could perform the ADL tasks independently [16]. That 
Table 3 Simple and multiple regression analysis of the effect on ADL difficulty score

\begin{tabular}{|c|c|c|c|c|c|c|c|c|}
\hline \multirow[t]{2}{*}{ Variable } & \multicolumn{4}{|l|}{ Univariate } & \multicolumn{4}{|l|}{ Multivariate } \\
\hline & $\begin{array}{l}\text { Unstandardized } \\
\text { regression } \\
\text { coefficient }\end{array}$ & $\begin{array}{l}95 \% \text { confidence } \\
\text { interval }\end{array}$ & $\begin{array}{l}\text { Standardized } \\
\text { regression } \\
\text { coefficient ( } \beta \text { ) }\end{array}$ & $P$ value & $\begin{array}{l}\text { Unstandardized } \\
\text { regression } \\
\text { coefficient }\end{array}$ & $\begin{array}{l}95 \% \text { confidence } \\
\text { interval }\end{array}$ & $\begin{array}{l}\text { Standardized } \\
\text { regression } \\
\text { coefficient ( } \beta \text { ) }\end{array}$ & $P$ value \\
\hline \multicolumn{9}{|l|}{ a: U/L ADL difficulty } \\
\hline Intercept & & & & & 28.16 & 7.14 to 49.18 & & \\
\hline Age (years) & -0.41 & -0.66 to -0.17 & -0.25 & 0.001 & 0.001 & -0.19 to 0.19 & 0.001 & 0.99 \\
\hline Male & 1.71 & 0.10 to 3.33 & 0.16 & 0.04 & 0.07 & -1.48 to 1.61 & 0.01 & 0.93 \\
\hline Body mass index $\left(\mathrm{kg} / \mathrm{m}^{2}\right)$ & 0.80 & 0.29 to 1.30 & 0.23 & 0.002 & 0.34 & -0.04 to 0.73 & 0.10 & 0.08 \\
\hline Living alone & -1.89 & -3.83 to 0.06 & 0.14 & 0.06 & -0.17 & -1.52 to 1.17 & -0.01 & 0.80 \\
\hline SARC-F score (points) & -3.63 & -4.18 to -3.08 & -0.70 & $<0.001$ & -2.68 & -3.41 to -1.95 & -0.52 & $<0.001$ \\
\hline Hemodialysis & -4.38 & -6.21 to -2.55 & -0.34 & $<0.001$ & 0.55 & -1.25 to 2.35 & 0.04 & 0.55 \\
\hline Grip strength (kg) & 0.75 & 0.56 to 0.95 & 0.50 & $<0.001$ & 0.31 & 0.06 to 0.56 & 0.21 & 0.02 \\
\hline Usual gait speed (m/s) & 16.77 & 13.26 to 20.29 & 0.53 & $<0.001$ & 4.61 & -0.24 to 9.46 & 0.16 & 0.06 \\
\hline \multicolumn{9}{|l|}{ b: L/L ADL difficulty } \\
\hline Intercept & & & & & 45.07 & 24.26 to 65.89 & & \\
\hline Age (years) & -0.45 & -0.73 to -0.17 & -0.24 & 0.002 & -0.04 & -0.23 to 0.15 & -0.02 & 0.65 \\
\hline Male & 0.74 & -1.14 to 2.62 & 0.06 & 0.44 & 0.68 & -0.84 to 2.21 & 0.05 & 0.38 \\
\hline Body mass index $\left(\mathrm{kg} / \mathrm{m}^{2}\right)$ & 0.26 & -0.34 to 0.85 & 0.07 & 0.39 & -0.03 & -0.41 to 0.35 & -0.01 & 0.89 \\
\hline Living alone & -1.57 & -3.82 to 0.68 & -0.10 & 0.17 & 0.70 & -0.64 to 2.03 & 0.05 & 0.30 \\
\hline SARC-F score (points) & -4.65 & -5.21 to -4.10 & -0.78 & $<0.001$ & -3.36 & -4.08 to -2.63 & -0.56 & $<0.001$ \\
\hline Hemodialysis & -6.39 & -8.41 to -4.36 & -0.43 & $<0.001$ & -0.17 & -1.95 to 1.61 & -0.01 & 0.85 \\
\hline Grip strength (kg) & 0.62 & 0.38 to 0.86 & 0.36 & $<0.001$ & -0.09 & -0.34 to 0.16 & -0.05 & 0.50 \\
\hline Usual gait speed (m/s) & 23.93 & 20.47 to 27.38 & 0.72 & $<0.001$ & 11.61 & 6.81 to 16.42 & 0.35 & $<0.001$ \\
\hline
\end{tabular}

$A D L$ : activities of daily living, $L / L$ : lower limb, U/L upper limb

is, measuring ADL difficulty may aid the appropriate grading of ADL ability in outpatients undergoing HD. Therefore, it seems important to evaluate ADL difficulty to prevent the progression of decline of ADL dependency in elderly patients undergoing HD.

Previous studies have shown the relationship between the decline in kidney function and ADL dependency or difficulty. A 2-year longitudinal study with communitydwelling older adults reported that chronic kidney disease was a risk factor for decline of basic and instrumental ADL [29]. In a large-scale cross-sectional national survey, the percentage of patients who had ADL dependency and difficulty increased as the chronic kidney disease stage became more severe [30]. Moreover, another observational study showed that the initiation of HD was associated with increased dependency on seven basic ADL tasks in elderly patients with end-stage renal disease [31]. The present study showed that many elderly patients undergoing HD had moderate to severe difficulty in ADL tasks compared with communitydwelling elderly adults. Patients undergoing HD have multiple comorbidities [1, 3], an inactive lifestyle [32], and physical frailty [4, 5], and these factors form a vicious circle. Therefore, we consider that the deterioration of kidney function leading to HD and the initiation of HD adversely affected ADL difficulty similar to ADL dependency.

Multiple regression analysis revealed that sarcopenia and physical function were determinants of ADL difficulty even after adjusting for patient characteristics and presence of HD. According to some reports, the incidence of sarcopenia was high $(>30 \%)$ and sarcopenia was reported to be associated with lower grip strength in elderly patients undergoing HD [33, 34]. It is known that patients undergoing HD have poor physical function and physical frailty $[35,36]$. These previous reports support the results of the present study, which showed that these elderly patients had more sarcopenia and poor physical functions. Moreover, physical frailty was strongly related to the dependency on four basic ADL tasks in these patients [37]. Therefore, this may explain how the deterioration in physical function affected ADL difficulty which was an early predictor of ADL dependency.

Some limitations of the present study should be acknowledged. First, the result from this study could not address the effects of ADL difficulty on ADL dependency in patients undergoing HD because this study had a cross-sectional design. Physical frailty progresses 
a: U/L ADL difficulty

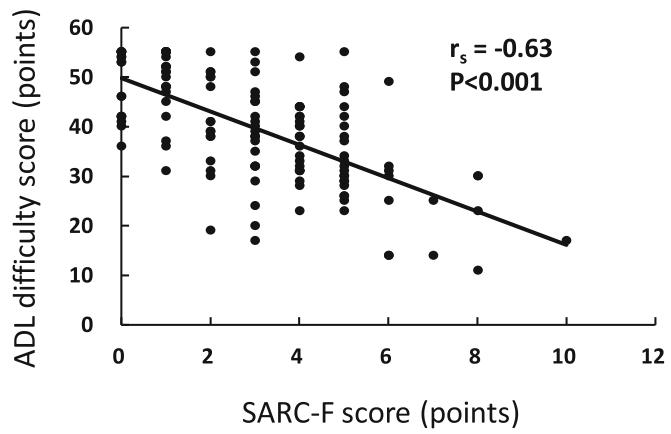

b: L/L ADL difficulty
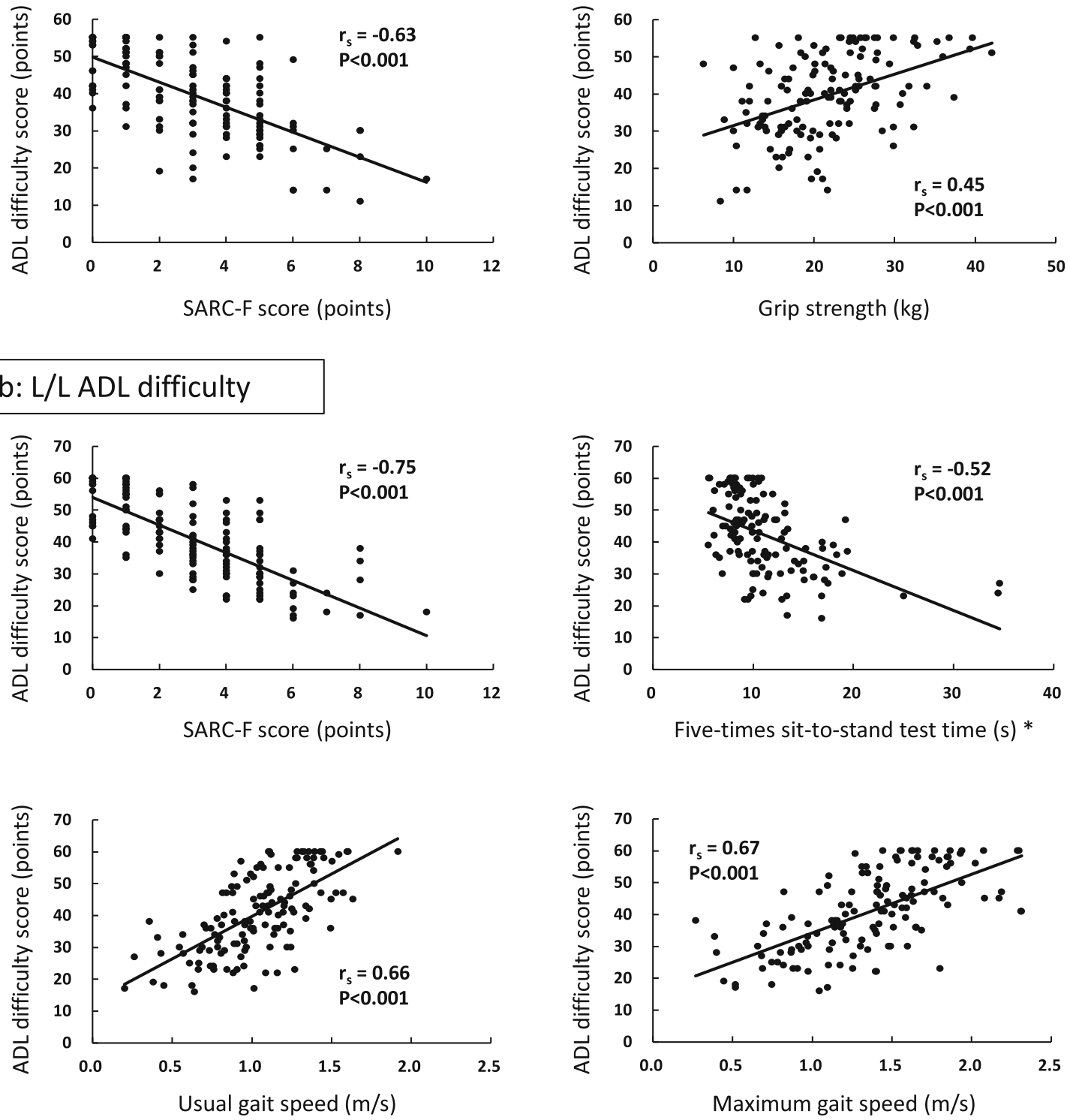

Five-times sit-to-stand test time $(\mathrm{s}) *$

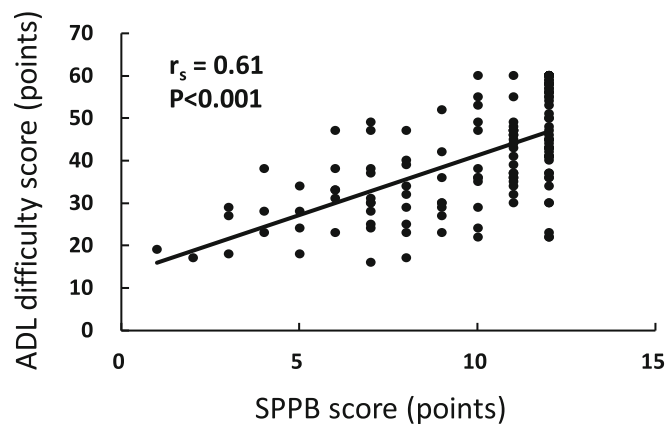

score (points)

Fig. 3 Scatter plots of physical function and ADL difficulty score in the hemodialysis group. * Twelve hemodialysis patients could not complete the five-times sit-to-stand test. ADL: activities of daily living, L/L: lower limb, SPPB: Short physical performance battery, U/L: upper limb 
gradually and results in ADL difficulty and ADL dependency in elderly adults $[38,39]$. Therefore, further research is needed to observe long-term changes in ADL difficulty and to examine the relationship with ADL dependency in these elderly patients. Second, the study participants were patients undergoing HD who did not have arthralgia, myalgia, or motor paralysis. Elderly patients undergoing HD tend to have multiple comorbidities $[1,3]$. In such patients with severe comorbidities, the characteristics of physical function and ADL difficulty may be different from the results of this study.

\section{Conclusions}

Ambulatory elderly patients undergoing HD had poorer physical function and stronger ADL difficulty than control community-dwelling elderly adults. There was an association between the ADL difficulty and sarcopenia or poor physical function among these patients. These findings among patients undergoing HD are useful, given the well-known association between the poor physical function and ADL dependency in the general elderly population.

\section{Abbreviations}

ADL: Activities of daily living; HD: Hemodialysis; L/L: Lower limb; SARCF: Strength, assistance in walking, rise from a chair, climb stairs, and falls; SPPB: Short physical performance battery; U/L: Upper limb

\section{Acknowledgements}

The authors appreciate the contributions of the staff in the dialysis unit and the subjects participated in this study.

\section{Authors' contributions}

TK, YI, TW, MU, HW, SS, AY, and AM made substantial contributions to the conception and design of the work. TK, YI, TW, YM, SK, YK, and JT performed measurements of the physical function and ADL difficulty. TK and YI prepared and analyzed the dataset. TK and AM interpreted the data and drafted the work. All authors read and approved the final version of the manuscript.

\section{Funding}

This research was supported by JSPS KAKENHI (grant number 26350631).

\section{Availability of data and materials}

The datasets used and/or analyzed during the current study are available from the corresponding author on reasonable request.

\section{Ethics approval and consent to participate}

The present study was performed according to the ethical standards Declaration of Helsinki and approved by the ethics committees of Kitasato University (approval number: 2016-014) and Tokyo University of Technology (approval number: E18HS-018). Informed consent was obtained from all individual participants included in the present study.

\section{Consent for publication}

Not applicable.

\section{Competing interests}

The authors declare that they have no competing interests.

\section{Author details}

'Department of Physical Therapy, School of Health Sciences, Tokyo University of Technology, 5-23-22 Nishikamata, Ota-ku, Tokyo 144-8535, Japan.

${ }^{2}$ Department of Rehabilitation Sciences, Kitasato University Graduate School of Medical Sciences, Sagamihara, Kanagawa, Japan. ${ }^{3}$ Department of Clinical Psychology, Tsurukawa Sanatorium Hospital, Tokyo, Japan. ${ }^{4}$ Department of Health Science, School of Allied Health Sciences, Kitasato University, Sagamihara, Japan. ${ }^{5}$ Department of Rehabilitation, School of Allied Health Sciences, Kitasato University, Sagamihara, Japan. ${ }^{6}$ Department of Hemodialysis Center, Sagami Circulatory Organ Clinic, Sagamihara, Japan.

Received: 23 July 2019 Accepted: 27 November 2019

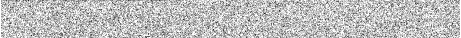

\section{References}

1. Canaud B, Tong L, Tentori F, Akiba T, Karaboyas A, Gillespie B, et al. Clinica practices and outcomes in elderly hemodialysis patients: results from the Dialysis Outcomes and Practice Patterns Study (DOPPS). Clin J Am Soc Nephrol. 2011;6(7):1651-62 https://doi.org/10.2215/cjn.03530410.

2. Masakane I, Taniguchi M, Nakai S, Tsuchida K, Wada A, Ogata S, et al. Annual Dialysis Data Report 2016. JSDT Renal Data Registry. Ren Replace Ther. 2018 4:45 https://doi.org/10.1186/s41100-018-0183-6.

3. Foote C, Ninomiya T, Gallagher M, Perkovic V, Cass A, McDonald SP, et al. Survival of elderly dialysis patients is predicted by both patient and practice characteristics. Nephrol Dial Transplant. 2012;27(9):3581-7 https://doi.org/10. 1093/ndt/gfs096.

4. Johansen KL, Chertow GM, Jin C, Kutner NG. Significance of frailty among dialysis patients. J Am Soc Nephrol. 2007;18(11):2960-7 https://doi.org/10. 1681/asn.2007020221.

5. van Loon IN, Goto NA, Boereboom FTJ, Bots ML, Verhaar MC, Hamaker ME. Frailty screening tools for elderly patients incident to dialysis. Clin J Am Soc Nephrol. 2017;12(9):1480-8 https://doi.org/10.2215/cjn.11801116.

6. Cook WL, Jassal SV. Functional dependencies among the elderly on hemodialysis. Kidney Int. 2008;73(11):1289-95 https://doi.org/10.1038/ki. 2008.62.

7. Kutner NG, Zhang R, Huang Y, Painter P. Gait speed and mortality, hospitalization, and functional status change among hemodialysis patients: a US Renal Data System special study. Am J Kidney Dis. 2015;66(2):297-304 https://doi.org/10.1053/j.ajkd.2015.01.024.

8. Bossola M, Di Stasio E, Antocicco M, Pepe G, Tazza L, Zuccala G, et al. Functional impairment is associated with an increased risk of mortality in patients on chronic hemodialysis. BMC Nephrol. 2016;17(1):72 https://doi. org/10.1186/s12882-016-0302-y.

9. Jassal SV, Karaboyas A, Comment LA, Bieber BA, Morgenstern H, Sen A, et al. Functional dependence and mortality in the international Dialysis Outcomes and Practice Patterns Study (DOPPS). Am J Kidney Dis. 2016;67(2): 283-92 https://doi.org/10.1053/j.ajkd.2015.09.024.

10. Farrington K, Covic A, Aucella F, Clyne N, de Vos L, Findlay A, et al. Clinical Practice Guideline on management of older patients with chronic kidney disease stage $3 \mathrm{~b}$ or higher (eGFR $<45 \mathrm{~mL} / \mathrm{min} / 1.73 \mathrm{~m} 2$ ). Nephrol Dial Transplant. 2016;31(suppl 2):ii1-66 https://doi.org/10.1093/ndt/gfw356.

11. Yamagata K, Hoshino J, Sugiyama H, Hanafusa N, Shibagaki Y, Komatsu $Y$, et al. Clinical practice guideline for renal rehabilitation: systematic reviews and recommendations of exercise therapies in patients with kidney diseases. Ren Replace Ther. 2019;5:28 https://doi.org/10.1186/ s41100-019-0209-8.

12. Hirvensalo M, Rantanen T, Heikkinen E. Mobility difficulties and physical activity as predictors of mortality and loss of independence in the community-living older population. J Am Geriatr Soc. 2000;48(5):493-8.

13. Julius M, Hawthorne VM, Carpentier-Alting P, Kneisley J, Wolfe RA, Port FK. Independence in activities of daily living for end-stage renal disease patients: biomedical and demographic correlates. Am J Kidney Dis. 1989;13(1):61-9.

14. Kavanagh NT, Schiller B, Saxena AB, Thomas IC, Kurella TM. Prevalence and correlates of functional dependence among maintenance dialysis patients. Hemodial Int. 2015;19(4):593-600 https://doi.org/10.1111/hdi. 12286.

15. Duruoz MT, Cerrahoglu L, Dincer-Turhan Y, Kursat S. Hand function assessment in patients receiving haemodialysis. Swiss Med Wkly. 2003; 133(31-32):433-8 https://doi.org/2003/31/smw-10216

16. Watanabe T, Kutsuna T, Yoneki K, Harada M, Shimoda T, Matsunaga Y, et al. Determinants of difficulty in activities of daily living in ambulatory patients undergoing hemodialysis. Ren Replace Ther. 2018;4:8 https://doi.org/10. 1186/s41100-018-0146-y. 
17. Liu J, Huang Z, Gilbertson DT, Foley RN, Collins AJ. An improved comorbidity index for outcome analyses among dialysis patients. Kidney Int 2010;77(2):141-51 https://doi.org/10.1038/ki.2009.413.

18. Malmstrom TK, Morley JE. SARC-F: a simple questionnaire to rapidly diagnose sarcopenia. J Am Med Dir Assoc. 2013;14(8):531-2 https://doi.org/ 10.1016/j.jamda.2013.05.018.

19. Woo J, Leung J, Morley JE. Validating the SARC-F: a suitable community screening tool for sarcopenia? J Am Med Dir Assoc. 2014;15(9):630-4 https://doi.org/10.1016/j.jamda.2014.04.021.

20. Mathiowetz V, Weber K, Volland G, Kashman N. Reliability and validity of grip and pinch strength evaluations. J Hand Surg Am. 1984;9(2):222-6.

21. Chen LK, Liu LK, Woo J, Assantachai P, Auyeung TW, Bahyah KS, et al. Sarcopenia in Asia: consensus report of the Asian Working Group for Sarcopenia. J Am Med Dir Assoc. 2014;15(2):95-101 https://doi.org/10.1016/j. jamda.2013.11.025

22. Lord SR, Murray SM, Chapman K, Munro B, Tiedemann A. Sit-to-stand performance depends on sensation, speed, balance, and psychological status in addition to strength in older people. J Gerontol A Biol Sci Med Sci. 2002;57(8):M539-43 https://doi.org/10.1093/gerona/57.8.m539.

23. Bohannon RW. Comfortable and maximum walking speed of adults aged 20-79 years: reference values and determinants. Age Ageing. 1997;26(1):15-9 https://doi.org/10.1093/ageing/26.1.15.

24. Studenski S, Perera S, Wallace D, Chandler JM, Duncan PW, Rooney E, et al. Physical performance measures in the clinical setting. J Am Geriatr Soc. 2003;51(3):314-22.

25. Dumurgier J, Elbaz A, Ducimetiere P, Tavernier B, Alperovitch A, Tzourio C. Slow walking speed and cardiovascular death in well functioning older adults: prospective cohort study. BMJ. 2009;339:b4460 https://doi.org/10. 1136/bmj.b4460.

26. Guralnik JM, Simonsick EM, Ferrucci L, Glynn RJ, Berkman LF, Blazer DG, et al. A short physical performance battery assessing lower extremity function: association with self-reported disability and prediction of mortality and nursing home admission. J Gerontol. 1994;49(2):M85-94.

27. Guralnik JM, Ferrucci L, Simonsick EM, Salive ME, Wallace RB. Lowerextremity function in persons over the age of 70 years as a predictor of subsequent disability. N Engl J Med. 1995;332(9):556-61 https://doi.org/10. 1056/nejm199503023320902.

28. Kutsuna T, Matsunaga A, Takagi Y, Motohashi S, Yamamoto K, Matsumoto T, et al. Development of a novel questionnaire evaluating disability in activities of daily living in the upper extremities of patients undergoing maintenance hemodialysis. Ther Apher Dial. 2011;15(2):185-94 https://doi.org/10.1111/j. 1744-9987.2010.00905.x.

29. Bowling CB, Sawyer P, Campbell RC, Ahmed A, Allman RM. Impact of chronic kidney disease on activities of daily living in community-dwelling older adults. J Gerontol A Biol Sci Med Sci. 2011;66(6):689-94 https://doi. org/10.1093/gerona/glr043.

30. Plantinga LC, Johansen K, Crews DC, Shahinian VB, Robinson BM, Saran R, et al. Association of CKD with disability in the United States. Am J Kidney Dis. 2011;57(2):212-27 https://doi.org/10.1053/j.ajkd.2010.08.016.

31. Kurella Tamura M, Covinsky KE, Chertow GM, Yaffe K, Landefeld CS, McCulloch CE. Functional status of elderly adults before and after initiation of dialysis. N Engl J Med. 2009;361(16):1539-47 https://doi.org/10.1056/ NEJMoa0904655.

32. Johansen $\mathrm{KL}$, Painter $\mathrm{P}$, Delgado C, Doyle J. Characterization of physical activity and sitting time among patients on hemodialysis using a new physical activity instrument. J Ren Nutr. 2015;25(1):25-30 https://doi.org/10. 1053/j.jrn.2014.06.012.

33. Bataille S, Serveaux M, Carreno E, Pedinielli N, Darmon P, Robert A. The diagnosis of sarcopenia is mainly driven by muscle mass in hemodialysis patients. Clin Nutr. 2017;36(6):1654-60 https://doi.org/10. 1016/j.clnu.2016.10.016.

34. Ren H, Gong D, Jia F, Xu B, Liu Z. Sarcopenia in patients undergoing maintenance hemodialysis: incidence rate, risk factors and its effect on survival risk. Ren Fail. 2016;38(3):364-71 https://doi.org/10.3109/0886022x. 2015.1132173

35. Chowdhury R, Peel NM, Krosch M, Hubbard RE. Frailty and chronic kidney disease: a systematic review. Arch Gerontol Geriatr. 2017;68:135-42 https:// doi.org/10.1016/j.archger.2016.10.007.

36. Painter P. Physical functioning in end-stage renal disease patients: update 2005. Hemodial Int. 2005;9(3):218-35 https://doi.org/10.1111/j.1492-7535. 2005.01136.x.
37. Kutner NG, Zhang R, Allman RM, Bowling CB. Correlates of ADL difficulty in a large hemodialysis cohort. Hemodial Int. 2014;18(1):70-7 https://doi.org/ 10.1111/hdi.12098

38. Fried LP, Tangen CM, Walston J, Newman AB, Hirsch C, Gottdiener J, et al. Frailty in older adults: evidence for a phenotype. J Gerontol A Biol Sci Med Sci. 2001;56(3):M146-56 https://doi.org/10.1093/gerona/56.3.m146.

39. Morley JE, Vellas B, van Kan GA, Anker SD, Bauer JM, Bernabei R, et al. Frailty consensus: a call to action. J Am Med Dir Assoc. 2013;14(6):392-7 https:// doi.org/10.1016/j.jamda.2013.03.022.

\section{Publisher's Note}

Springer Nature remains neutral with regard to jurisdictional claims in published maps and institutional affiliations.
Ready to submit your research? Choose BMC and benefit from:

- fast, convenient online submission

- thorough peer review by experienced researchers in your field

- rapid publication on acceptance

- support for research data, including large and complex data types

- gold Open Access which fosters wider collaboration and increased citations

- maximum visibility for your research: over $100 \mathrm{M}$ website views per year

At $\mathrm{BMC}$, research is always in progress.

Learn more biomedcentral.com/submissions 